\title{
Quantitative Evaluation of Bitterlich Sampling for Estimating Basal Area in Sparse Boreal Forests and Dense Tropical Forests
}

\author{
Wei Yang1*, Hideki Kobayashi², Kenlo Nishida Nasahara³, Rikie Suzuki², Akihiko Kondoh¹ \\ ${ }^{1}$ Center for Environmental Remote Sensing, Chiba University, Chiba, Japan \\ ${ }^{2}$ Department of Environmental Geochemical Cycle Research, Japan Agency for Marine-Earth Science and Technology, \\ Yokohama, Japan \\ ${ }^{3}$ Faculty of Life and Environmental Sciences, University of Tsukuba, Tsukuba, Japan \\ Email: *yangwei@chiba-u.jp
}

How to cite this paper: Yang, W., Kobayashi, H., Nasahara, K. N., Suzuki, R., \& Kondoh, A. (2017). Quantitative Evaluation of Bitterlich Sampling for Estimating Basal Area in Sparse Boreal Forests and Dense Tropical Forests. Open Journal of Forestry, 7, 143-156.

https://doi.org/10.4236/ojf.2017.72009

Received: January 4, 2017

Accepted: March 28, 2017

Published: March 31, 2017

Copyright (C) 2017 by authors and Scientific Research Publishing Inc. This work is licensed under the Creative Commons Attribution International License (CC BY 4.0).

http://creativecommons.org/licenses/by/4.0/

\begin{abstract}
Bitterlich sampling is an extensively used technique in worldwide forest inventories. Although it has been proved that estimates of basal area from Bitterlich sampling are mathematically unbiased, its precision for individual forest stands may be fairly poor. An extension of validation efforts to different forest biomes could therefore provide more comprehensive assessment and understanding of the Bitterlich sampling technique. In this study, this technique was quantitatively evaluated by using simulated sparse boreal forests and dense tropical forests from an empirical forest structure model (EFSM). Theoretical estimation of basal areas and practical estimation influenced by the hidden-tree effect were both compared with true basal areas of the simulated forests. The evaluation results indicated that: 1) Bitterlich sampling can yield acceptable accuracy and precision when the count number $(\mathrm{CN})$ of trees was set to 10 for the studied boreal and tropical forests with distinct characteristics, 2) the theoretical estimation of basal area can be improved by increasing the $\mathrm{CN}$ values for both forests, and 3) when the hidden-tree effect is encountered, the accuracy for tropical forests will be decreased by increasing the $\mathrm{CN}$ values, whereas the accuracy for boreal forests can still be improved. Accordingly, a relatively high $\mathrm{CN}$, at a reasonable cost, is recommended for sparse boreal forests to improve the accuracy of basal area estimation. In contrast, for dense tropical forests, a $\mathrm{CN}$ of ten is appropriate to mitigate the hidden-tree effect.
\end{abstract}

\section{Keywords}

Angle-Count Sampling, Basal Area, Forest Structure Modeling, Boreal Forests, Tropical Forests 


\section{Introduction}

Forests are crucial natural resources for human beings in terms of providing wooden products, recycling carbon dioxide $\left(\mathrm{CO}_{2}\right)$ into oxygen $\left(\mathrm{O}_{2}\right)$, regulating global climate, mitigating natural hazards, and so on. The acquisition of forest inventory data sets, such as biomass, basal area, and timber volume, not only effectively supports the rational development of government policy, but also provides information for the development and validation of terrestrial ecosystem models (e.g., Floyd et al., 2009) and satellite remote sensing algorithms (e.g., Suzuki et al., 2013). Consequently, forest inventories have been carried out to collect such data sets all over the world.

Sampling-based forest inventories have been proved be the most effective technique for estimating forest stand parameters. In general, there are the two main categories of in situ sampling methods (Pique et al., 2011): 1) fixed-radius sampling and 2) variable-radius sampling (also known as Bitterlich sampling, or angle-count sampling). The fixed-radius sampling counts all the trees within a fixed plot. In contrast, in the Bitterlich sampling, the trees are counted according to a probability that is proportional to their subtended angle to a predesignated observation point.

Bitterlich sampling is much more efficient than the fixed-radius method to estimate basal area, which is a key descriptor of a forest stand in the calculation of biodiversity indices (Motz et al., 2010) and the development of ecological models (e.g., Bugmann and Solomon, 2000). To estimate the basal area from the Bitterlich sampling, a basal area factor (BAF) needs to be first determined according to the forest characteristics. Trees are selected as being counted "in" or "out" of the samples according to the relationship between diameter at breast height (DBH) and their distance to the observation point. Trees whose subtended angle is greater than the predefined BAF are counted in, whereas other trees are counted out. Then the basal area is estimated to be the product of the number of trees counted in and the pre-chosen BAF (Bitterlich, 1984). It is crucial to designate an appropriate BAF in Bitterlich sampling, in order to get satisfactory estimation accuracies. Bitterlich (1984) recommended a benchmark minimum of 10 trees to be counted in per plot, while Avery and Burkhart (2001) stated that the most adequate BAF is largely dependent on the average tree size and distribution of trees to be sampled. For example, in the US, they found that an appropriate BAF should provide an average of 5 - 12 trees per sample point or even less (4- 8 trees), depending on the study region.

Previous studies have demonstrated that estimates of per-plot basal area by Bitterlich sampling are mathematically unbiased (e.g., Palley and Horwitz, 1961; Whyte and Tennent, 1975), but the precision for individual forest stands is often fairly poor in certain circumstances (Eastaugh and Hasenauer, 2014). Therefore, several studies have been conducted in different regions to evaluate the performance of Bitterlich sampling by comparison with fixed-radius sampling. These include studies in forests in southeast Texas, US (Grosenbaugh and Stover, 1957), the southern Appalachian Mountains of North Carolina, US (Packard and 
Radtke, 2007), and in a Mediterranean forest in northeast Spain (Pique et al., 2011). These studies concluded that the results produced using the two sampling methods were not significantly different. There have also been several studies using mathematic analysis or simulation approaches to evaluate and/or improve Bitterlich sampling. For example, Oderwald (1981) mathematically analyzed Bitterlich sampling to estimate basal area in forests with different spatial patterns. More recently, Eastaugh and Hasenauer (2013) theoretically analyzed the biases in volume increment estimates derived from successive Bitterlich sampling. Eastaugh and Hasenauer (2014) developed a multiple basal area factor (mBAF) method to improve the precision of per-plot basal area estimates by simulation analysis based on datasets from the Austrian National Forest Inventory.

An extension of the validation efforts to more different biome types could provide more comprehensive assessment and understanding of the performances of the Bitterlich sampling. Nevertheless, implementation of the validation activities using field plots is a very difficult task because it is quite time consuming and needs a large labor cost. Fortunately, modeling of forest structure can provide a controlled environment, in which pseudodata can be generated for any desired environmental conditions.

Consequently, the objective of this study was to quantitively evaluate the Bitterlich sampling method in sparse boreal and dense tropical forests, which are two distinct forest biomes of great importance for global terrestrial ecosystems. An empirical forest structure model (EFSM) was adopted to generate different kinds of boreal and tropical forest stands; and the performance of Bitterlich sampling was evaluated by comparing the estimated basal area with the true values of the generated forest stands. The hidden-tree effect on basal area estimation was also explicitly considered in the simulated sparse boreal and dense tropical forests.

\section{Materials and Methods}

\subsection{Collection of Allometric Equations}

\subsubsection{Black Spruce Forest at the Interior of Alaska, US}

The forest census data provided by Suzuki et al. (2013) were used in the modeling of a sparse boreal forest. Field investigations were conducted in September 2010 at the Poker Flat Research Range (PFRR, 65.12 N, 147.50 W, 250 m a.s.l.), which is located $50 \mathrm{~km}$ from Fairbanks, AK, US. The dominant species in the area is black spruce (Picea mariana), an evergreen needleleaf tree, with aboveground biomass around the study site ranging 6.6 - 50.7 $\mathrm{Mg} \mathrm{DW} \mathrm{ha}^{-1}$ (Suzuki et al., 2013). The measurements contained the horizontal positions (i.e., the $\mathrm{X}-\mathrm{Y}$ coordinates), canopy height $(\mathrm{H})$, and DBH of individual trees $(>1.3 \mathrm{~m})$ within a $30 \times 30 \mathrm{~m}^{2}$ forest plot. The stand density was 3978 trees ha ${ }^{-1}$ (357 trees in the 30 $\times 30 \mathrm{~m}^{2}$ plot), and the average $\mathrm{H}$ and $\mathrm{DBH}$ were $2.4 \pm 1.1 \mathrm{~m}$ and $1.2 \pm 0.079 \mathrm{~cm}$, respectively.

In this study, we made the allometric equations using the $\mathrm{H}$ as the independent variable, rather than the DBH in traditional forestry, according to the defi- 
nition in the adopted EFSM (Yang et al., 2016). Using on the in situ datasets collected at the PFRR, we derived a DBH estimation model for boreal black spruce forests with an $\mathrm{R}^{2}$ of 0.94 (see Table 1 for the equations). However, we did not have the measurements of crown radius (CR) and crown length (CL) for the forests. Therefore, the allometric relationships between $\mathrm{H}$ and both CR and CL for boreal black spruce forests were taken from Honer (1971), which presented the crown-radius equations for open-grown black spruce at the Petawawa Forest Experimental Station, Chalk River, Ontario.

\subsubsection{Tropical Forest in Southeast Asia}

To obtain allometric equations for typical tropical forests, we conducted literature surveys on data sets of $\mathrm{H}, \mathrm{CR}, \mathrm{CL}$, and $\mathrm{DBH}$ for the tropical forests. We finally found that Kira et al. (1989) presented three side-view pictures of Meranti forests located in Borneo, Indonesia. From these pictures, the H, CR, and CL for individual trees was extracted by converting the pixel-distance to an actual measurement metric (in meters). The parameters listed above were collected for trees with a height larger than $1.5 \mathrm{~m}$. Then we made the estimation models of CR and CL for the tropical forests, as shown in Table 1. It should be noted that both of the models are statistically significant, with an R2 higher than 0.8 . Due to the lack of in situ datasets of DBH, an estimation model from Kato et al. (1978) was used, which was developed using data collected from Pasoh Forest Reserve, Malaysia (Table 1).

\subsection{Generation of Simulated Sparse Boreal and Dense Tropical Forests}

An empirical forest structure model (EFSM) proposed by Yang et al. (2016) was adopted to generate typical boreal and tropical forest stands in this study. Typical sparse boreal black spruce forests and dense tropical forests were generated for a domain of $100 \times 100 \mathrm{~m}^{2}$ in two different ways. For boreal forests, the Hmin and Hmax were set as 1.5 and $6 \mathrm{~m}$, respectively, which were the measured minimum and maximum $\mathrm{H}$ values for PFRR. The input tree densities were changed from 2000 to 10,000 with an interval of 400 . Thus, 21 forests with different crown coverages were derived.

In contrast, for tropical forests, the Hmin was set as $5 \mathrm{~m}$, which means that we only counted trees higher than $5 \mathrm{~m}$, otherwise considered the understory layer, while the Hmax was changed from 30 to $50 \mathrm{~m}$ with an interval of $1 \mathrm{~m}$. The tree density corresponding to each Hmax value was determined based on the as-

Table 1. Allometric relationships for simulating boreal and tropical forests.

\begin{tabular}{cccc}
\hline Boreal Forests & \multicolumn{2}{c}{ Tropical Forests } \\
\hline Equations & Reference & Equations & Reference \\
$\mathrm{CR}(\mathrm{m})=-0.00029 \mathrm{H}^{2}+0.085 \mathrm{H}$ & Honer $(1971)$ & $\mathrm{CR}(\mathrm{m})=0.0019 \mathrm{H}^{2}+0.055 \mathrm{H}+0.35$ & This study \\
$\mathrm{CL}(\mathrm{m})=0.898 \mathrm{H}$ & Honer $(1971)$ & $\mathrm{CL}(\mathrm{m})=0.755 \mathrm{H}^{0.618}$ & This study \\
$\mathrm{DBH}(\mathrm{m})=-0.004 \mathrm{H}^{2}+0.0097 \mathrm{H}-0.0087$ & This study & $\mathrm{DBH}(\mathrm{m})=61 \mathrm{H} /(61-\mathrm{H})$ & Kato et al. (1978) \\
\hline
\end{tabular}


sumption that all of the available space was occupied by individual trees in closed tropical forests. An iteration strategy was used to determine the maximum acceptable tree density corresponding to each Hmax. A sufficiently small tree density was used as an initial input, and then the density was gradually increased until the overlap criterion could not be satisfied at a certain location. In this way, we obtained 21 tropical forests with very high crown coverage.

\subsection{Principle of Bitterlich Sampling for Estimating Basal Area}

For a tree with a stem radius of $r_{\mathrm{i}}$ (i.e., $\mathrm{DBH} / 2$ ), and the distance between the tree and observer at point $O$ is $R_{\mathrm{i}}$ (Figure 1), half of the subtended angle, $\alpha$, can be expressed as:

$$
\sin \alpha=\frac{r_{i}}{R_{i}}
$$

and then,

$$
R_{i}=\frac{r_{i}}{\sin \alpha}
$$

Thus, the area of the virtual circular plot for a tree with stem radius of $r_{\mathrm{i}}$ is:

$$
A_{i}=\pi \cdot R_{i}^{2}=\pi \cdot\left(\frac{r_{i}}{\sin \alpha}\right)^{2}
$$

The basal area per hectare then results from:

$$
\begin{aligned}
G_{i} & =n_{i} \cdot \pi \cdot r_{i}^{2} \cdot \frac{10,000}{A_{i}}=10,000 \cdot \frac{n_{i} \cdot \pi \cdot r_{i}^{2}}{\pi\left(\frac{r_{i}}{\sin \alpha}\right)^{2}} \\
& =10,000 \cdot(\sin \alpha)^{2} \cdot n_{i}
\end{aligned}
$$

where $n_{i}$ is the number of trees with a stem radius of $r_{i}$ in a plot with area $A_{i}$. We define $k=1000 \cdot(\sin \alpha)^{2}$ which is usually referred to as the basal area factor (BAF).

The basal area per hectare of all trees is therefore as follows:

$$
G_{h a}=k \cdot \sum_{i=1}^{M} n_{i}=k \cdot N
$$

where $N$ is the number of trees with a $k$ value larger than a predetermined BAF. We refer to it as the count number $(\mathrm{CN})$ of trees in this study.

\subsection{Simulation of the Sampling Strategy}

Bitterlich sampling was simulated using nine observation positions, which were

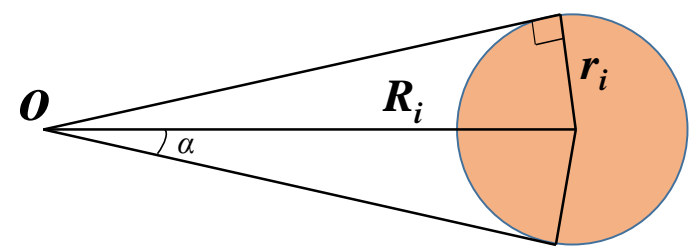

Figure 1. Illustration of the principle of Bitterlich sampling. 
evenly located every $25 \mathrm{~m}$ along the $\mathrm{X}$ and $\mathrm{Y}$ axis in a domain of $100 \times 100 \mathrm{~m}^{2}$. Therefore, the position of the observer was at the X-Y coordinates of $(25,25)$, $(25,50),(25,75),(50,25),(50,50),(50,75),(75,25),(75,50)$, and $(75,75) . \mathrm{Al}-$ though this might require a fairly high labor cost from a practical perspective, it does help mitigate the heterogeneity of the forest landscapes.

The estimation of basal area was derived by multiplying the predetermined basal area factor (BAF) by the count number $(\mathrm{CN})$. The $\mathrm{CN}$ values will be changed by taking into consideration of hidden-tree effect or not. The hidden-tree effect refers to the phenomenon that certain trees cannot be counted in because they are located behind other trees. It would be encountered in practical inventories, especially in some dense forest stands. In this study, two kinds of estimations of basal areas were undertaken: one was named as theoretical estimation by ignoring the hidden-tree effect, that is, all the trees whose subtended angle is greater than the predetermined BAF were counted in no matter they are hidden by other trees or not; the other is named as practical estimation by taking into consideration of the hidden-tree effect. The estimated basal areas were calculated for each observation point, then their averages were regarded as the final estimations for the simulated $100 \times 100 \mathrm{~m}^{2}$ forest stands. It can be anticipated that the estimation of basal area will be decreased by the hidden-tree effect. The simulations can help quantitatively understand to what extent the estimation would be decreased in different types of forests.

\subsection{Accuracy and Precision Assessment}

Two indices, namely the mean normalized bias (MNB) and normalized root mean square error (NRMS), were used to assess accuracy. These indices are defined as follows:

$$
\mathrm{MNB}=\operatorname{mean}\left(\varepsilon_{i}\right)
$$

and

$$
\mathrm{NRMS}=\operatorname{stdev}\left(\varepsilon_{i}\right)
$$

where $\varepsilon_{i}=\left(X_{\text {esti }, i}-X_{\text {true }, i}\right) / X_{\text {true }, i} \%$, and $X_{\text {esti }, i}$ and $X_{\text {true }, i}$ are the estimated and true basal areas, respectively. The MNB denotes the average bias in the estimation, and NRMS denotes the relative random uncertainty of the results.

\section{Results}

\subsection{Properties of Simulated Forests}

Figure 2 shows six examples of the simulated forest landscapes. The simulated boreal black spruce forests were very sparse, with large proportions of understory exposed (panels a-c), even when the tree density was as high as 10,011 . This is because the simulated trees had a relatively small crown radius. Crown-level clumping effect can be observed due to the use of a Neyman distribution to determine the locations of the individual trees. In contrast, the simulated tropical forests were very dense, with few understory layers viewable from the nadir view 


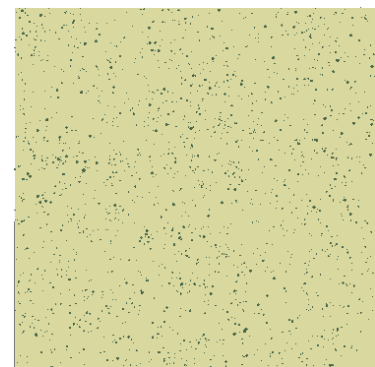

(a) Boreal, TD = 2023

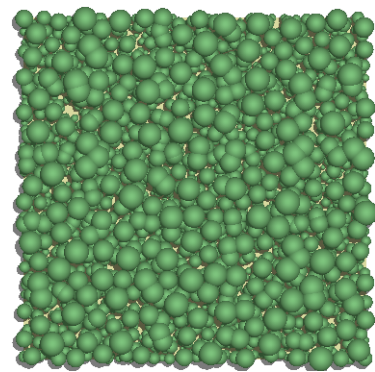

(d) Tropical, $\mathrm{H}_{\max }=30 \mathrm{~m}$

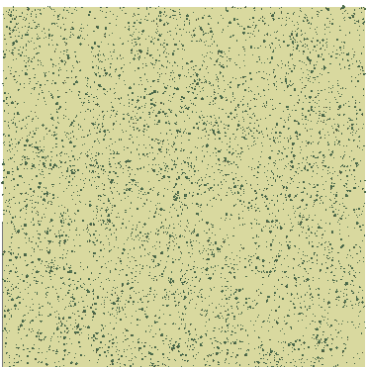

(b) Boreal, TD $=6007$

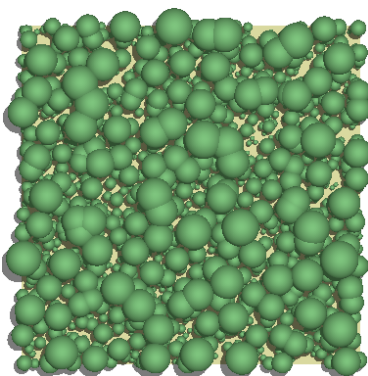

(e) Tropical, $\mathrm{H}_{\max }=40 \mathrm{~m}$

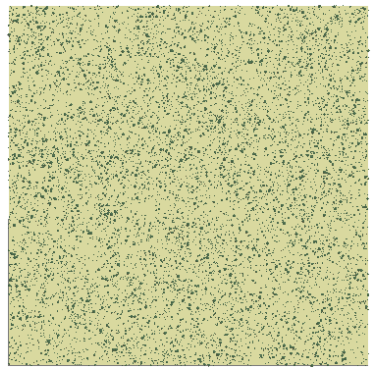

(c) Boreal, TD = 10011

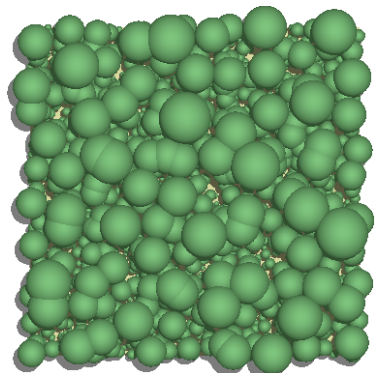

(f) Tropical, $\mathrm{H}_{\max }=50 \mathrm{~m}$

Figure 2. Nadir view of simulated sparse boreal (a)-(c) and dense tropical (d)-(f) forests.

Table 2. Descriptive statistics of the structural parameters for simulated boreal and tropical forests.

\begin{tabular}{ccccccc}
\hline & & $\begin{array}{c}\text { Canpoy } \\
\text { height }(\mathrm{m})\end{array}$ & $\begin{array}{c}\text { DBH } \\
(\mathrm{m})\end{array}$ & $\begin{array}{c}\text { Crown } \\
\text { Radius }(\mathrm{m})\end{array}$ & $\begin{array}{c}\text { Tree } \\
\text { Density }\left(\mathrm{ha}^{-1}\right)\end{array}$ & $\begin{array}{c}\text { Crown } \\
\text { Cover }(\%)\end{array}$ \\
\hline \multirow{2}{*}{ Boreal } & Max & 6.00 & 0.0175 & 0.45 & 10011 & 11.95 \\
& Mean & 2.43 & 0.0061 & 0.18 & 6058 & 7.23 \\
& Min & 1.50 & 0.0025 & 0.11 & 2023 & 2.48 \\
& Max & 49.98 & 0.691 & 7.83 & 2403 & 96.53 \\
& Mean & 14.34 & 0.058 & 1.66 & 1808 & 93.68 \\
& Min & 5.00 & 0.014 & 0.68 & 1505 & 89.74 \\
\hline
\end{tabular}

(panels $\mathrm{d}-\mathrm{f}$ ). It is obvious that some small trees were located beneath larger trees. This is because there was adequate open space under the big trees due to the small ratio of crown length to tree height in tropical forests.

The statistical description of the simulated forests' characteristics is summarized in Table 2. The actual tree density in boreal forests $\left(2023-10,011 \mathrm{ha}^{-1}\right)$ displayed some variability around the input values $\left(2000-10,000 \mathrm{ha}^{-1}\right)$ resulting from the Neyman distribution. For the tropical forests, the acceptable maximum tree density corresponding to the Hmax was $1505-2403 \mathrm{ha}^{-1}$, with an average of $1808 \mathrm{ha}^{-1}$. The boreal forests had very low crown coverage, averaging $7.23 \%$ and ranging from $2.48 \%$ to $11.95 \%$. In contrast, the crown coverage of simulated tropical forests was very high, at an average of $93.68 \%$, and ranging from $89.74 \%$ to $96.53 \%$.

\subsection{Evaluation Results for Boreal Forests}

Bitterlich sampling was first applied to the boreal black spruce forests to estimate 
their basal areas. Determination of an appropriate BAF is crucial for accurate estimations from Bitterlich sampling. Different BAF values will lead to different CN values of trees. Bitterlich (1984) recommended a benchmark minimum of 10 trees per point. Therefore, an estimation of basal area using a $\mathrm{CN}$ of 10 was compared to the true values for all 21 simulated boreal forests (Figure 3 ). The sampling yielded a theoretical estimation with an average bias (i.e., MNB) of $9.26 \%$, and relative random uncertainty (i.e., NRMS) of $8.93 \%$. For the practical estimation of basal area (i.e., with the hidden-tree effect taken into consideration), a slightly lower MNB and higher NRMS of 7.97\% and 9.51\%, respectively, were derived. These results indicate that an acceptable accuracy can be obtained when a $\mathrm{CN}$ of 10 is used for sparsely distributed boreal forests, and the hiddentree effect would not influence the estimation accuracy very much.

To determine if the performance of Bitterlich sampling can be improved by increasing the $\mathrm{CN}$ value, the basal area was estimated using $\mathrm{CN}$ values from 10 to 40 with an interval of 5 , with the BAF values ranging from 0.01 to 0.15 . Figure 4 shows the trajectories of MNB and NRMS for the theoretical and practical estimation of basal area with changing CN values. Both the MNB and NRMS from the theoretical estimation show decreasing trends with an increasing $\mathrm{CN}$. The results indicate that the accuracy and precision of basal area estimation can be theoretically improved by increasing the $\mathrm{CN}$. When the hidden-tree effect is taken into consideration (i.e., the practical estimation), the accuracy of Bitterlich sampling can still be improved, with the MNB decreasing from $8 \%$ to $-0.3 \%$ by increasing the $\mathrm{CN}$ value (Figure 4(a)). However, it is not anticipated that the estimate including the hidden-tree effect would yield a higher accuracy and a slightly lower precision than the theoretical estimation (Figure 4(a) \& Figure 4(b)). The

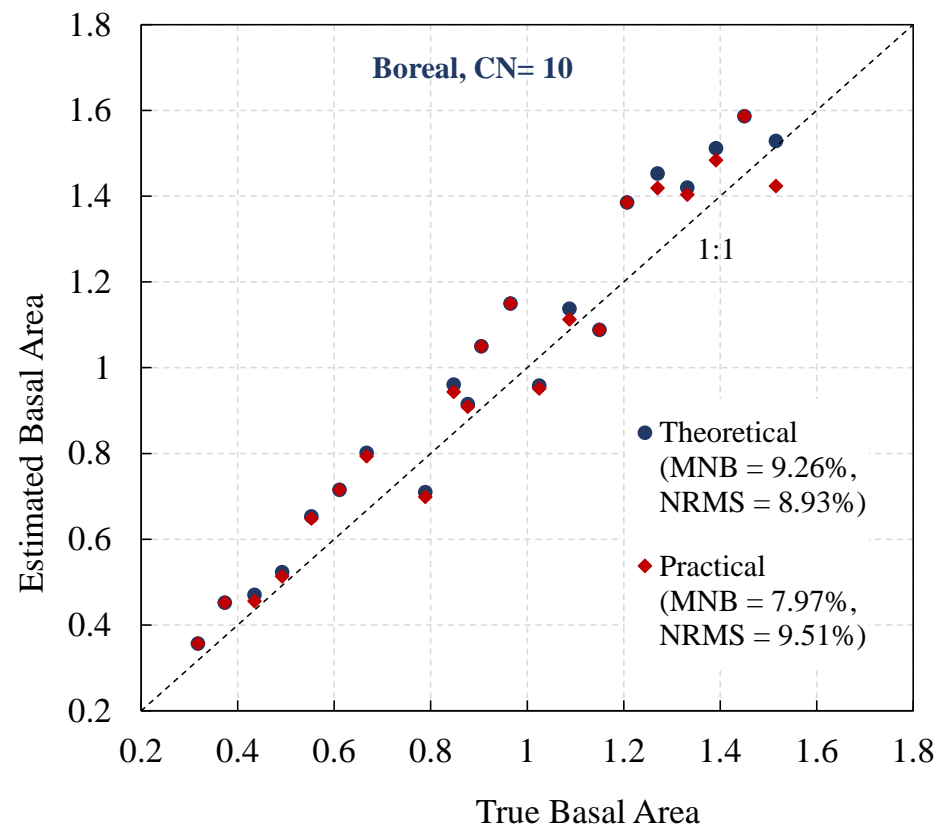

Figure 3. Comparison of the theoretical and practical estimation of basal area using 10 as the count number $(\mathrm{CN})$ of trees for boreal forests. The practical estimation takes the hidden-tree effect into consideration. 

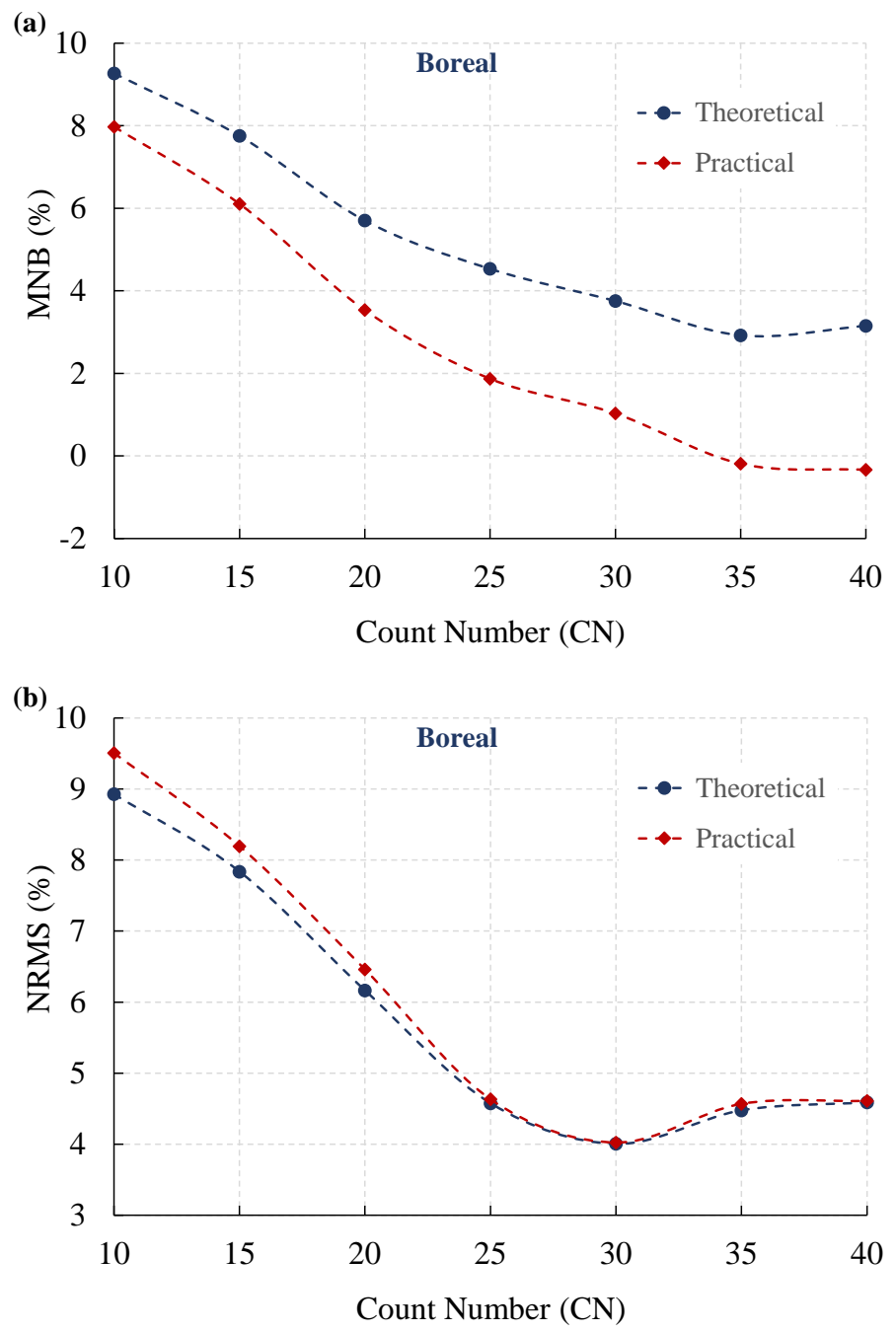

Figure 4. Trajectories of (a) mean normalized bias (MNB) and (b) normalized root mean square error (NRMS) versus increasing $\mathrm{CN}$ for the theoretical and practical estimation of basal area in Boreal forests.

overestimation of the theoretical results is consistent with the performance of Bitterlich sampling in forests in Catalonia, northeast Spain, as presented in Pique et al. (2011), due mainly to the heterogeneity of tree distributions. The hidden-tree effect would reduce the estimation of basal area, and therefore result in a better accuracy.

\subsection{Evaluation Results for Tropical Forests}

The Bitterlich sampling was then applied to the 21 simulated tropical forests. Figure 5 compares the true and estimated basal area using a CN of 10. The Bitterlich sampling yielded a very high theoretical accuracy, with an MNB lower than $3 \%$, and a high precision with an NRMS lower than $6 \%$. The theoretical estimation of Bitterlich sampling for the dense tropical forests outperformed that for the sparse boreal forests with the MNB and NRMS decreasing from $9.26 \%$ to $2.62 \%$, and from $8.93 \%$ to $5.88 \%$, respectively (Figure 3 vs. Figure 5 ). When the hidden-tree effect was taken into consideration (i.e., the practical estimation), a 


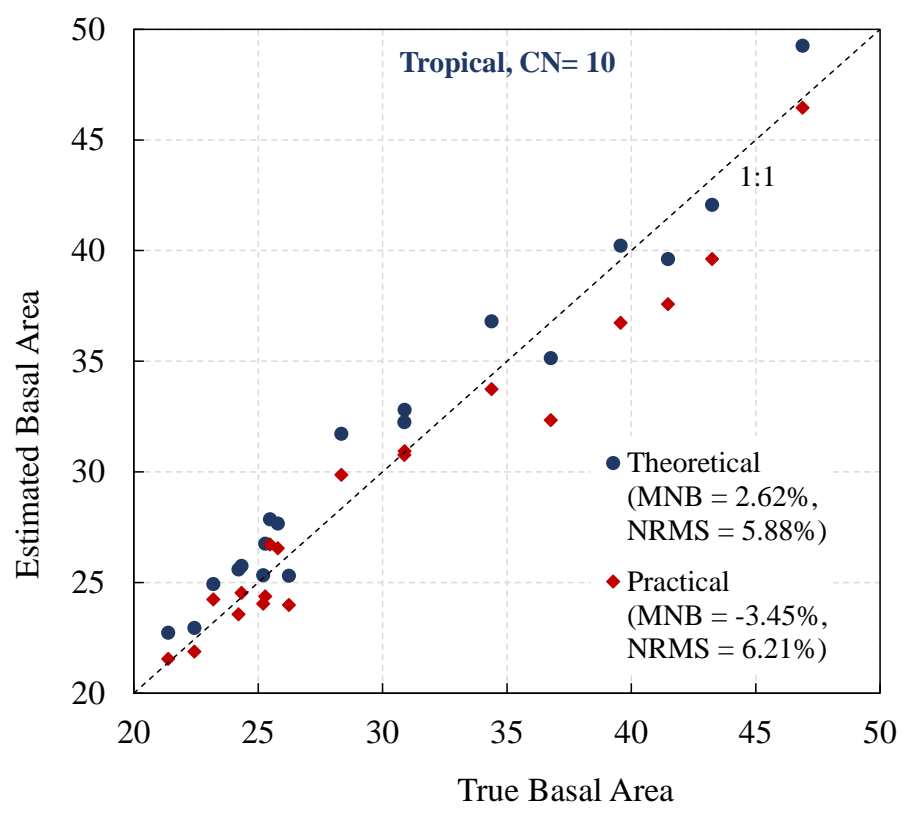

Figure 5. Comparison of the theoretical and practical estimation of basal area using CN of 10 for tropical forests.

clear underestimation was observed, with an MNB of $-3.45 \%$, and a similar relative random uncertainty, with an NRMS of $6.21 \%$. This indicates that the hidden-tree effect reduces the accuracy of Bitterlich sampling when a $\mathrm{CN}$ of 10 is used.

The performance of Bitterlich sampling was also evaluated using different $\mathrm{CN}$ values for the dense tropical forests. The theoretical estimation was slightly improved when the MNB was slightly decreased and when the $\mathrm{CN}$ was increased from 10 to 40 (the BAFs values ranged from 0.5 to 5.0). All of the accuracies were satisfactory, with an average bias lower than 3\% (Figure 6(a)). However, when the hidden-tree effect was considered, the estimation accuracy decreased rapidly from $-3.5 \%$ to $-15.5 \%$. This is because the number of hidden trees will increase when a smaller BAF (corresponding to a larger $\mathrm{CN}$ ) is used. In contrast, both the theoretical and practical estimations yielded similar values of NRMS, ranging from $2.5 \%$ to $6.2 \%$ (Figure $6(\mathrm{~b})$ ), which indicates that the hidden-tree effect did not significantly reduce the estimation of precision for dense tropical forest.

\section{Discussion and Conclusion}

In this study, we quantitatively evaluated the performances of Bitterlich sampling method for estimation the basal areas of two distinct forest types: sparse boreal forests and dense tropical forests. These forests are playing important roles in global terrestrial ecosystems. The vegetation in northern middle and high latitudes is more sensitive to climate change, and temperature in this region is changing most rapidly (IPCC, 2013). On the other hand, tropical forests account for over $2 / 3$ of live terrestrial plant biomass (Pan et al., 2013), and exchange more $\mathrm{CO}_{2}$ with the atmosphere than any other biome (Beer et al., 2010). 

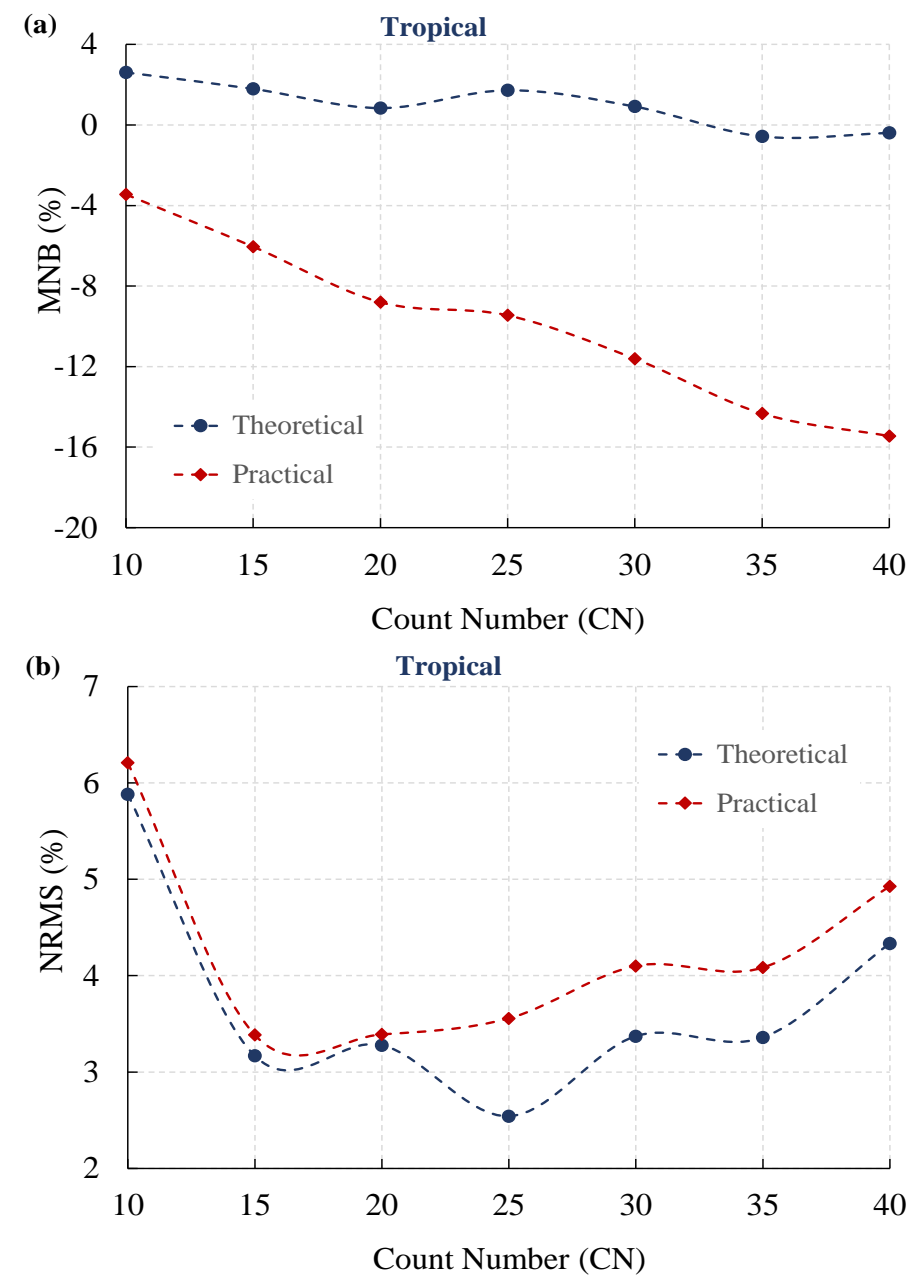

Figure 6. Trajectories of (a) MNB and (b) NRMS versus increasing CN for the theoretical and practical estimation of basal area in tropical forests.

Because of the difficulties in obtaining field measured, an empirical forest structure model (EFSM, Yang et al., 2016) was applied to generated different forest stands. The EFSM was originally developed to generate forest landscapes for deriving 3-D canopy radiative transfer simulations. It can provide the realistic scenes of tree locations and canopy sizes.

The Bitterlich sampling was evaluated by comparing the estimated basal area with the true values of the simulated forest stands. The evaluation results indicate that:

1) It yields an acceptable accuracy and precision when the $\mathrm{CN}$ of trees is set as 10 for both boreal and tropical forests. The hidden-tree effect would not significantly affect the performance when the $\mathrm{CN}$ is set to 10 .

2) For both boreal and tropical forests, the theoretical estimation of basal area can be improved by increasing the $\mathrm{CN}$ value. This is consistent with a validation study conducted in a Mediterranean forest in northeast Spain (Pique et al., 2011).

3) When the hidden-tree effect is encountered, the accuracy for tropical forests will decrease when the $\mathrm{CN}$ value is increased, although the accuracy for 
boreal forests can still be improved.

Accordingly, we recommend using a relatively high $\mathrm{CN}$ for sparse boreal forests to improve the estimation accuracy of basal area. In contrast, for dense tropical forests, a $\mathrm{CN}$ of 10 is sufficient to mitigate the hidden-tree effect. For example, when a $\mathrm{CN}$ of 40 was used for sparse boreal forest, Bitterlich sampling yielded an average bias (i.e., $\mathrm{MNB}$ ) of $-0.3 \%$, and a relative random uncertainty (i.e., NRMS) of $4.6 \%$, and when a $\mathrm{CN}$ of 10 was used for dense tropical forests, an MNB of $3.4 \%$ and an NRMS of $6.2 \%$ were achieved.

It is worth noting that in practical inventories, the hidden-tree effect can be overcome to some extent by stepping to the left or right of the observation point, meanwhile maintain the same distance to the hidden tree. However, experiences of an observer are highly required in different inventory works. Moreover, it cannot be ascertained that all the hidden trees can be counted in this way.

Besides the hidden-tree effect, there are more factors that may influence the performances of Bitterlich sampling. For example, the actual shape of a tree stem is elliptical, rather than perfectly circular as assumed in the Bitterlich theory. Another nontrivial factor is the measurement error resulting from an observer's subjective judgment of a tree being counted "in" or "out" based on a predefined BAF. Training of highly experienced observers is as important as theoretical and simulation analyses, to derive accurate and unbiased estimations.

In addition to basal area, Bitterlich sampling has also been used to estimate other forest parameters, such as tree density and diameter distributions (Pique et al., 2011). Nevertheless, Bitterlich (1984) stated that the estimation of density and diameter class distributions from angular counting is less efficient than the estimation of basal area. Moreover, several studies have focused on the use of Bitterlich sampling theory to estimate forest stand variables, such as total stand volume (Packard and Radtke, 2007), tree competition indices (Stage and Ledermann, 2008), and canopy cover (Stenberg et al., 2008). More extensive assessments of Bitterlich theory in these applications will be the focus of future studies.

\section{Acknowledgements}

This research was conducted under the JAXA GCOM Research Announcement (the 4th RA102 and the 6th RA 111) and the JAMSTEC-IARC Collaboration Study. We thank Dr. Y. Ono for assisting data collection for tropical forests.

\section{References}

Avery, T. E., \& Burkhart, H. (2001). Forest Measurements (5th ed.). New York, NY: McGraw-Hill.

Beer, C., Reichstein, M., Tomelleri, E. et al. (2010). Terrestrial Gross Carbon Dioxide Uptake: Global Distribution and Covariation with Climate. Science, 329, 834-838. https://doi.org/10.1126/science.1184984

Bitterlich, W. (1984). The Relascope Idea. Relative Measurements in Forestry. Farnham Royal: Commonwealth Agricultural Bureaux.

Bugmann, H. K. M., \& Solomon, A. M. (2000). Explaining Forest Composition and Biomass across Multiple Biogeographical Regions. Ecological Applications, 10, 95-114. 


\section{https://doi.org/10.1890/1051-0761(2000)010[0095:EFCABA]2.0.CO;2}

Eastaugh, C. S., \& Hasenauer, H. (2013). Biases in Volume Increment Estimates Derived from Successive Angle Count Sampling. Forest Science, 59, 1-14. https://doi.org/10.5849/forsci.11-007

Eastaugh, C. S., \& Hasenauer, H. (2014). Improved Estimates of Per-Plot Basal Area from Angle Count Inventories. iForest-Biogeosciences and Forestry, 7, 178-185. https://doi.org/10.3832/ifor1158-007

Floyd, M. L., Clifford, M., Cobb, N. S., Hanna, D., Delph, R., Ford, P., \& Turner, D. (2009). Relationship of Stand Characteristics to Drought-Induced Mortality in Three Southwestern Piñon-Juniper Woodlands. Ecological Applications, 19, 1223-1230. https://doi.org/10.1890/08-1265.1

Grosenbaugh, L. R., \& Stover, W. S. (1957). Point-Sampling Compared with Plot-Sampling in Southeast Texas. Forest Science, 3, 2-14.

Honer, T. G. (1971). Crown Shape in Open- and Forest-Grown Balsam Fir and Black Spruce. Canadian Journal of Forest Research, 1, 203-207. https://doi.org/10.1139/x71-027

IPCC (2013). Climate Change 2013: The Physical Science Basis. In T. F. Stocker, D. Qin, G.-K. Plattner, M. Tignor, S. K. Allen, J. Boschung, A. Nauels, Y. Xia, V. Bex, \& P. Midgley (Eds.), Contribution of Working Group I to the Fifth Assessment Report of the Intergovernmental Panel on Climate Change. Cambridge and New York, NY: Cambridge University Press.

Kato, R., Tadaki, Y., \& Ogawa, F. (1978). Plant Biomass and Growth Increment Studies in Pasoh Forest. Malayan Nature Journal, 30, 211-224.

Kira, T., Furukawa, H., Miyawaki, A., Katou, M., Iwatsuki, K., Hotta, M., Yoda, K., Ogino, K. et al. (1989). Botany, Agriculture and Forestry in Southeast Asia. Tokyo: Japan Society for the Promotion of Science.

Motz, K., Sterba, H., \& Pommerening, A. (2010). Sampling Measures of Tree Diversity. Forest Ecology and Management, 260, 1985-1996.

Oderwald, R. G. (1981). Comparison of Point and Plot Sampling Basal Area Estimators. Forest Science, 27, 42-48.

Packard, K. C., \& Radtke, P. J. (2007). Forest Sampling Combining Fixed- and Variable-Radius Sample Plots. Canadian Journal of Forest Research, 37, 1460-1471. https://doi.org/10.1139/X06-321

Palley, M. N., \& Horwitz, L. G. (1961). Properties of Some Random and Systematic Point Sampling Estimators. Forest Science, 7, 52-65.

Pan, Y., Birdsey, R. A., Phillips, O. L., \& Jackson, R. B. (2013). The Structure, Distribution, and Biomass of the World's Forests. Annual Review of Ecology, Evolution, and Systematics, 44, 593-622. https://doi.org/10.1146/annurev-ecolsys-110512-135914

Pique, M., Obton, B., Condes, S., \& Saura, S. (2011). Comparison of Relascope and Fixed-Radius Plots for the Estimation of Forest stand Variables in Northeast Spain: An Inventory Simulation Approach. European Journal of Forest Research, 130, 851-859. https://doi.org/10.1007/s10342-010-0477-x

Stage, A. R., \& Ledermann, T. (2008). Effects of Competitor Spacing in a New Class of Individual-Tree Indices of Competition: Semi-Distance-Independent Indices Computed for Bitterlich versus Fixed-Area Plots. Canadian Journal of Forest Research, 38, 890-898. https://doi.org/10.1139/X07-192

Stenberg, P., Korhonen, L., \& Rautiainen, M. (2008). A Relascope for Measuring Canopy Cover. Canadian Journal of Forest Research, 38, 2545-2550.

https://doi.org/10.1139/X08-081 
Suzuki, R., Kim, Y., \& Ishii, R. (2013). Sensitivity of the Backscatter Intensity of ALOS/ PALSAR to the Above-Ground Biomass and Other Biophysical Parameters of Boreal Forest in Alaska. Polar Science, 7, 100-112.

Whyte, A. G. D., \& Tennent, R. B. (1975). Improving Estimates of Stand Basal Area in Working Plan Inventories. New Zealand Journal of Forestry, 20, 134-147.

Yang, W. \& Kobayashi, H. (2016). An Empirical Forest Landscape Simulator for Driving 3-D Canopy Radiative Transfer Models. In Proceedings of The 60th Spring Conference of The Remote Sensing Society of Japan (pp. 55-56). Narashino: The Remote Sensing Society of Japan.

Submit or recommend next manuscript to SCIRP and we will provide best service for you:

Accepting pre-submission inquiries through Email, Facebook, LinkedIn, Twitter, etc. A wide selection of journals (inclusive of 9 subjects, more than 200 journals)

Providing 24-hour high-quality service

User-friendly online submission system

Fair and swift peer-review system

Efficient typesetting and proofreading procedure

Display of the result of downloads and visits, as well as the number of cited articles Maximum dissemination of your research work

Submit your manuscript at: http://papersubmission.scirp.org/

Or contact ojf@scirp.org 